MATEC Web of Conferences 46, 03001 (2016)

DOI: $10.1051 /$ matecconf $/ 20164603001$

(C) Owned by the authors, published by EDP Sciences, 2016

\title{
Fire exposed facades: Numerical modelling of the LEPIR2 testing facility
}

\author{
Virginie Dréan, Renaud Schillinger and Gildas Auguin \\ Efectis France, Saint Aubin, France
}

\begin{abstract}
LEPIR2 testing facility is aimed to evaluate the fire behaviour of construction solutions implemented on facade according with the experimental evaluation required by the French Technical Specification 249 (IT249) of the safety regulation. It aims to limit the risks of fire spreading by facades to upper levels. This facility involves a wood crib fire in the lower compartment of a full scale two levels high structure. Flames are coming outside from the compartment through windows openings and develop in front of the facade. Computational fluids dynamics simulations are carried out with the FDS code (Fire Dynamics Simulator) for two full-scale experiments performed by Efectis France laboratory. The first objective of this study is to evaluate the ability of numerical model to reproduce quantitative results in terms of gas temperatures and heat flux on the tested facade for further evaluation of fire performances of an insulation solution. When experimental results are compared with numerical calculations, good agreement is found out for every quantities and each test. The proposed models for wood cribs and geometry give correct thermal loads and flames shape near the tested facade.
\end{abstract}

\section{INTRODUCTION}

Development of external insulation facade solutions for construction is in great expansion because of economic and environmental considerations. The requirements provided by the French Technical Specification 249 (IT249) [1] of the safety regulation should help limiting the risks of fire spreading by facades to upper levels in case of fire occurring in a building.

The justification for facades not complying with the IT 249 technical requirements consists in a full scale test called LEPIR2 (for Experimental 2 levels Local For Real Fire) defined by the French ordinance of September 10th, 1970 [2]. The facility consists in two bunk rooms: two complete levels (R0 and R+1) and a starting of a third level $(\mathrm{R}+2)$. The lower level $(\mathrm{R} 0)$ contains the fire sources, consisting in two calibrated wood cribs representing a generalized cellulosic fire. The fire load attempts to simulate the standard ISO fire curve [3] in the first 30 minutes of the test. The floor between the ground level (R0) and the upper level $(\mathrm{R}+1)$ can be positioned at different heights.

The implementation of this test is restrictive because it requires the testing of a full scale facade. Moreover its cost may be a limitation for solution technologies development.

The use of numerical simulations is then particularly indicated in order to analyse LEPIR 2 test results for a given facade solution, and in order to assess extending configurations after a validating

This is an Open Access article distributed under the terms of the Creative Commons Attribution License 2.0, which permits unrestricted use, distribution, and reproduction in any medium, provided the original work is properly cited. 


\section{MATEC Web of Conferences}

test. Indeed, to allow for subsequent evaluation of the tested facade, the prediction of the thermal loads imparted to the facade materials is needed.

In this context, a numerical LEPIR2 model was developed with the FDS code (version 5) ("Fire Dynamics Simulator"). This computational fluid dynamics (CFD) code, developed by the American institute NIST [4-6], is widely used in the fire safety community.

This paper presents the preliminary studies performed to develop and validate this virtual testing facility. Any insulation material or cladding is considered on the facade, so that the facility is only made of concrete. So, the presented studies focus only on calibration tests. The following step, consisting in the implementation of an insulation material in front of the facade to evaluate the fire behaviour of facade solution is not exhibited here.

The physical phenomena to model with FDS in the case of LEPIR2 tests are primarily the burning of wood cribs in the fire compartment, then the flames exiting outside the openings and spreading along the facade.

The phenomenon of external flames is described and studied in [6]. For those flames existing outside of a compartment, it is necessary that they be supplied by leaving unburned combustion gases through the opening. The unburnt fuel gases left are then transported outside by convection where they react with the ambient air, itself driven in the outer flame and the thermal plume.

The dimensions of the external flames are mainly dependent on the air flow rates through the compartment openings. The geometry of the openings determines the shape of the stream of hot gases escaping from the compartment. The gas velocity at the opening determines the travelled horizontal distance, before the effect of buoyancy forces deflects the flames in the vertical direction.

The external thermal plume is naturally accompanied by air entrainment which leads the cooling of ascending hot gases. In the case where there is a wall above the opening, air entrainment is limited to one side. It contributes to a plume closer to the wall under the suction pressure effect. Therefore, the reattachment of the outer flames to the facade will be well modelled to properly assess the thermal loads transmits to the tested wall.

\section{LEPIR 2 TEST FACILITY}

\subsection{Structure}

The structure of LEPIR2 facility is regulated by Ordinance [1] modified by an application protocol [2].

It consists in two superposed rooms made of reinforced concrete with a thickness of $200 \mathrm{~mm}$ : two complete levels ( $\mathrm{R} 0$ and $\mathrm{R}+1)$, and the beginning of a third level $(\mathrm{R}+2)$. An opening is installed at the rear side of the ground level. It is provided with a door, and can be more or less closed during the test in order to control the incoming and outgoing air flow in the compartment. Windows are arranged in front of the two levels and the frames are made of PVC.

The typical construction is presented in Fig. 1.

\subsection{Fire load}

The fire load during the test consists in two wood cribs, standardized by [2] and laid on the floor of the R0 compartment.

Normalized cribs are made of softwood with density $480+/-50 \mathrm{~kg} / \mathrm{m}^{3}$ and moisture content between 9 and $15 \%$. Each crib consists in 3 different stacks (lower, medium, higher) (Fig. 2) with total dimensions of $1000 \times 1000 \times 1800 \mathrm{~mm}(\mathrm{~W} \times \mathrm{L} \times \mathrm{H})$ and mass of $300 \mathrm{~kg}(600 \mathrm{~kg}$ for the two cribs). The cribs are located in the lower compartment, at a distance of $100 \mathrm{~mm}$ from the front wall.

Steel trays filled with a mixture of heptane and fuel oil are placed under the fire loads for the ignition. 


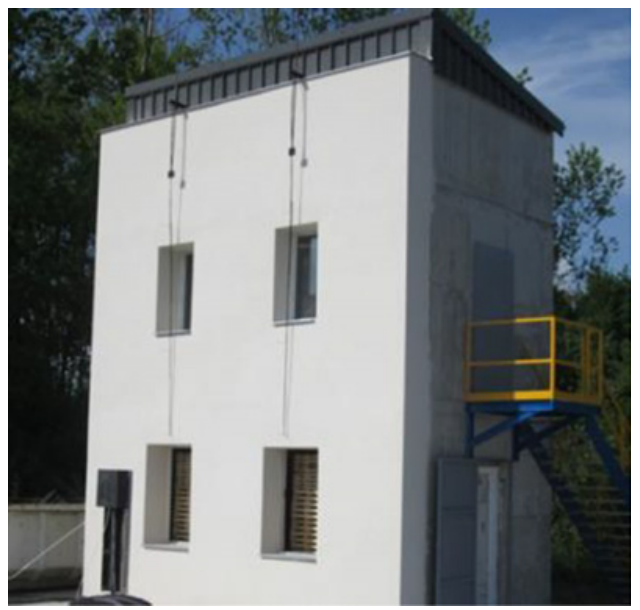

Figure 1. View of the Efectis LEPIR 2 facility.
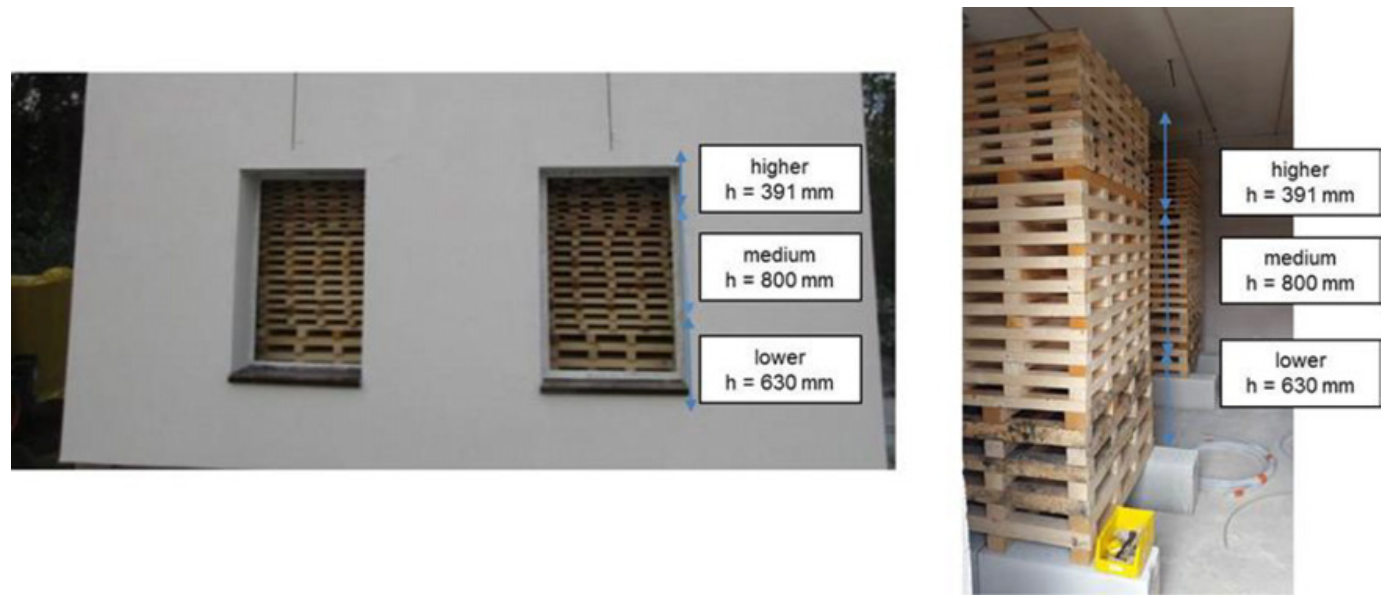

Figure 2. Fire load in the LEPIR2 facility.

The temperature of the hot gases near the compartment roof must then approach the ISO curve in the first 30 minutes of the test.

\subsection{Instrumentation}

To measure the evolution of the hot gas temperature and radiation during the test, $8 \mathrm{~mm}$ diameter Inconel type thermocouples are located within the fire compartment and on the exterior of the building, $150 \mathrm{~mm}$ from the tested facade to observe the outer flames propagation (Fig. 3).

The validation criteria to be controlled are:

- During the 30 minutes of the test, no ignition or flame propagation, lasting more than 20 seconds at the start of the third level facade, so no drilling of the facade is observed,

- No lateral spread of the inflammation of the facade on its entire width,

- No flame passage to the upper floor from the facade / floor junction, 


\section{MATEC Web of Conferences}

a)

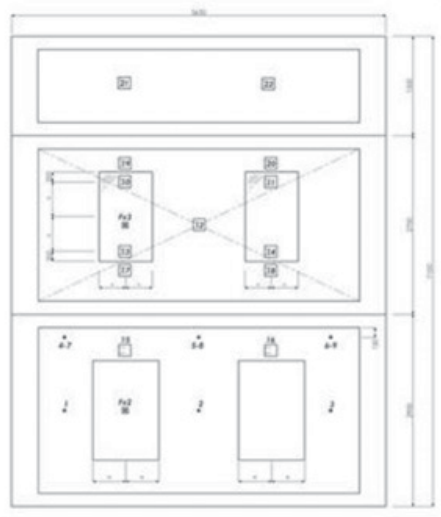

b)

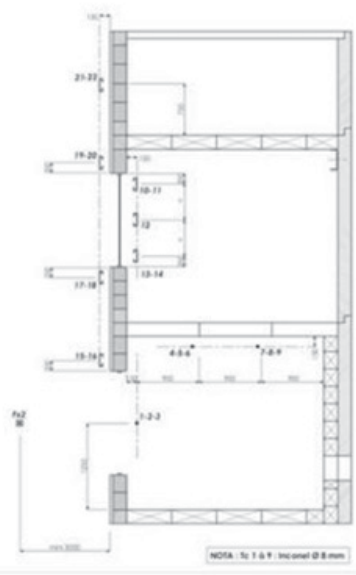

c)

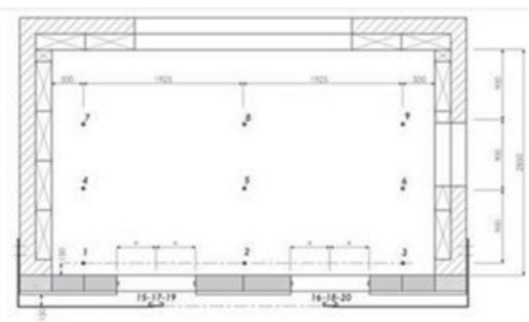

Figure 3. Location of instrumentation (thermocouples and plate thermometers) in LEPIR 2 facility a) front facade b) lateral view c) top view of the R0 compartment.

- No passing of hot gases having a temperature above $350^{\circ} \mathrm{C}$ trough the facade / floor junction,

- No temperature rises above $180^{\circ} \mathrm{C}$ on the unexposed side of the floor $50 \mathrm{~mm}$ back from the facade.

\subsection{Calibration tests}

During the two calibration tests performed, called respectively A and B tests, the facade exposed to external flame consists only of inert concrete with a $200 \mathrm{~mm}$ thickness.

The simulation of these tests allows validating the proposed model for the geometry (mesh, boundary conditions) and the fire source, without the influence of a facade construction solution.

\section{NUMERICAL SIMULATIONS}

\subsection{CFD code}

FDS is a computational code in fluid dynamics that incorporates a combustion model with a mixture fraction approach and a large eddy scale model (LES) for the description of turbulent flows.

This tool allows 3D modelling of the computational domain. It takes into account heat transfer conditions at walls (1D heat equation solved in solids), and ventilation conditions. 
a)

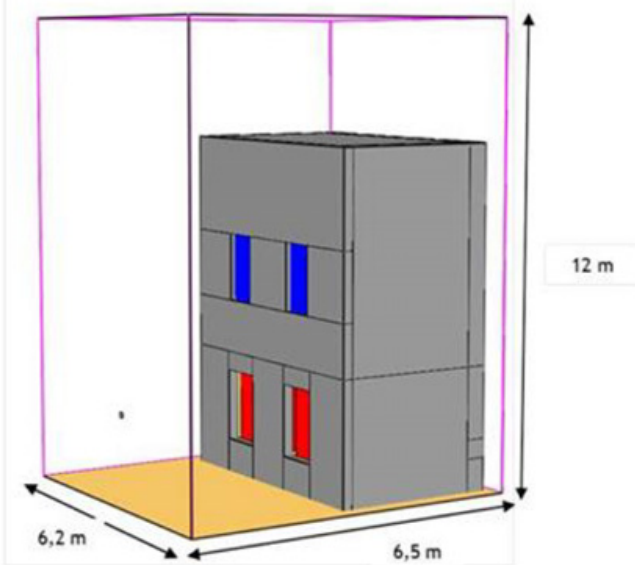

b)

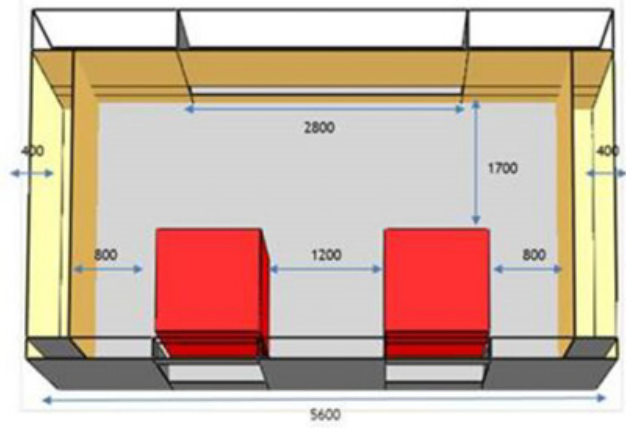

Figure 4. Numerical modelling of LEPIR II facility a) construction b) top view of the R0 (fire) compartment.

a)

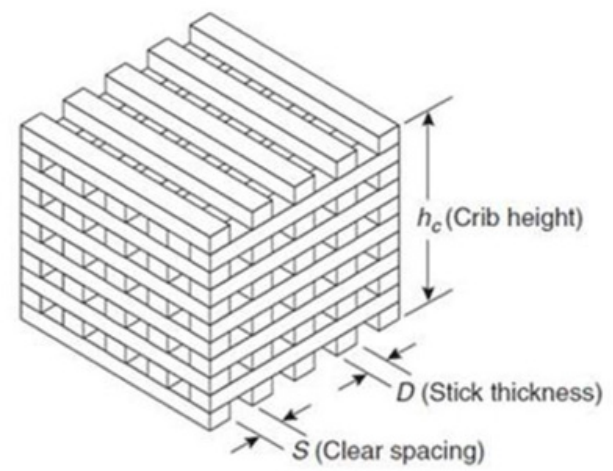

b)

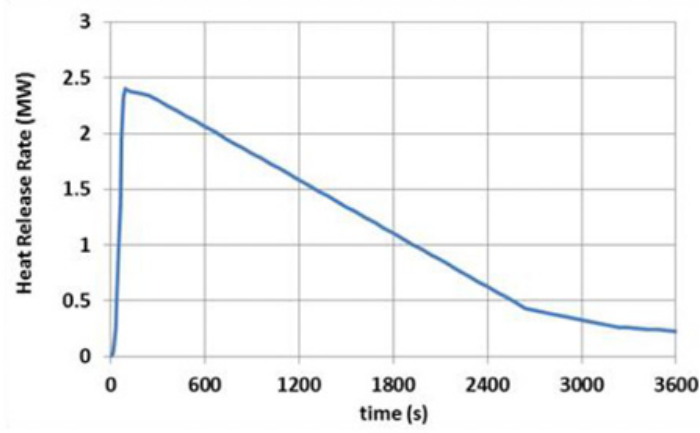

Figure 5. a) Wood crib representation for the burning rate evaluation [9] b) evaluated HRR for a single wood crib used in LEPIR 2.

\subsection{LEPIR2 construction}

The size of the computational domain is $6.5 \times 6.2 \times 12 \mathrm{~m}$ approximately. The dimensions of the test construction are adapted regarding the mesh size (Fig. 4). Grid size of $0.1 \times 0.1 \times 0.1 \mathrm{~m}$ is considered for the flame zone $(\mathrm{R} 0$ and $\mathrm{R}+1)$, and $0.2 \times 0.2 \times 0.2 \mathrm{~m}$ for the flameless zone $(\mathrm{R}+2)$. These dimensions permit to capture the main phenomena of combustion and ventilation, with a reasonable calculation time.

A condition of a zero gradient pressure (open) is imposed at the domain boundaries, except on the ground, considered as a $20^{\circ} \mathrm{C}$ surface. The boundaries of the domain are far enough from the construction to have no influence. The thermal properties for concrete structures are provided in [8].

In Fig. 4, the fire sources are represented by red blocks (R0), the windows by the blue surfaces $(\mathrm{R}+1)$. One of the windows is modelled bare inside of the facade, and the other bare outside. Glazing is modelled using thermal properties and radiation absorption coefficient inside the material. 
TEST A
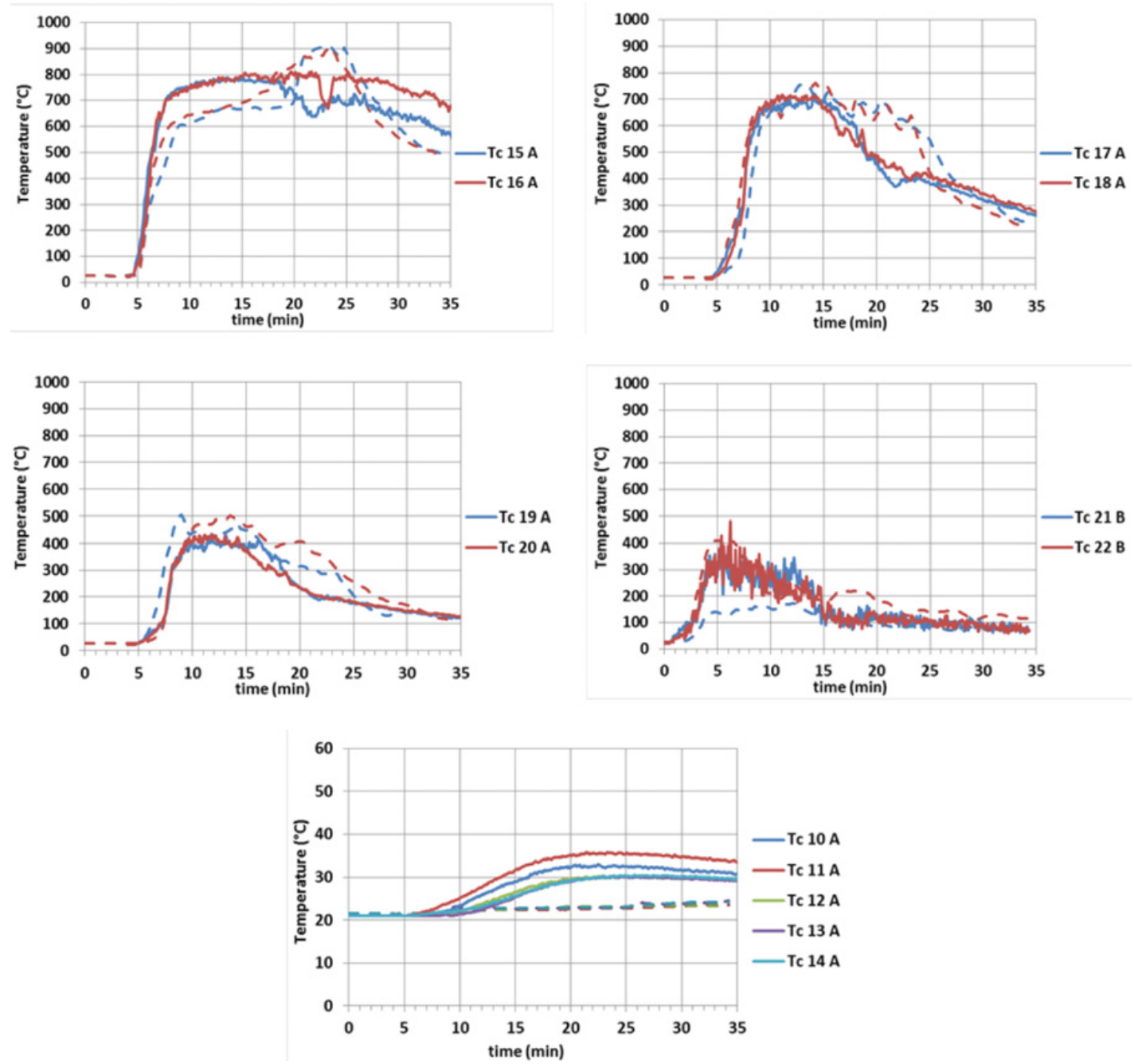

Figure 6. Comparison of experimental (dotted lines) and numerical (solid lines) gas temperatures $150 \mathrm{~mm}$ in front of the facade and in $\mathrm{R}+1$ compartment for the A calibration test of LEPIR2.

During the tests, the ventilation shutter at the rear side of the fire compartment can be opened or closed to regulate the air inflow and thus the wood cribs burning. The times and rates of opening are indicated in the test reports. However, the simulations are performed with the shutter opened.

\subsection{Fire load model}

The stoichiometric equation for the overall combustion reaction of wood is:

$\mathrm{C}_{3,4} \mathrm{H}_{6,2} \mathrm{O}_{2,5}+3,62\left(\mathrm{O}_{2}+3,76 \mathrm{~N}_{2}\right) \rightarrow 3,31 \mathrm{CO}_{2}+3,10 \mathrm{H}_{2} \mathrm{O}+0,01 \mathrm{CO}+0,07 \mathrm{C}_{\text {suies }}+13,61 \mathrm{~N}_{2}$.

A heat of combustion of $14 \mathrm{MJ} / \mathrm{kg}$ is used. 
TEST B
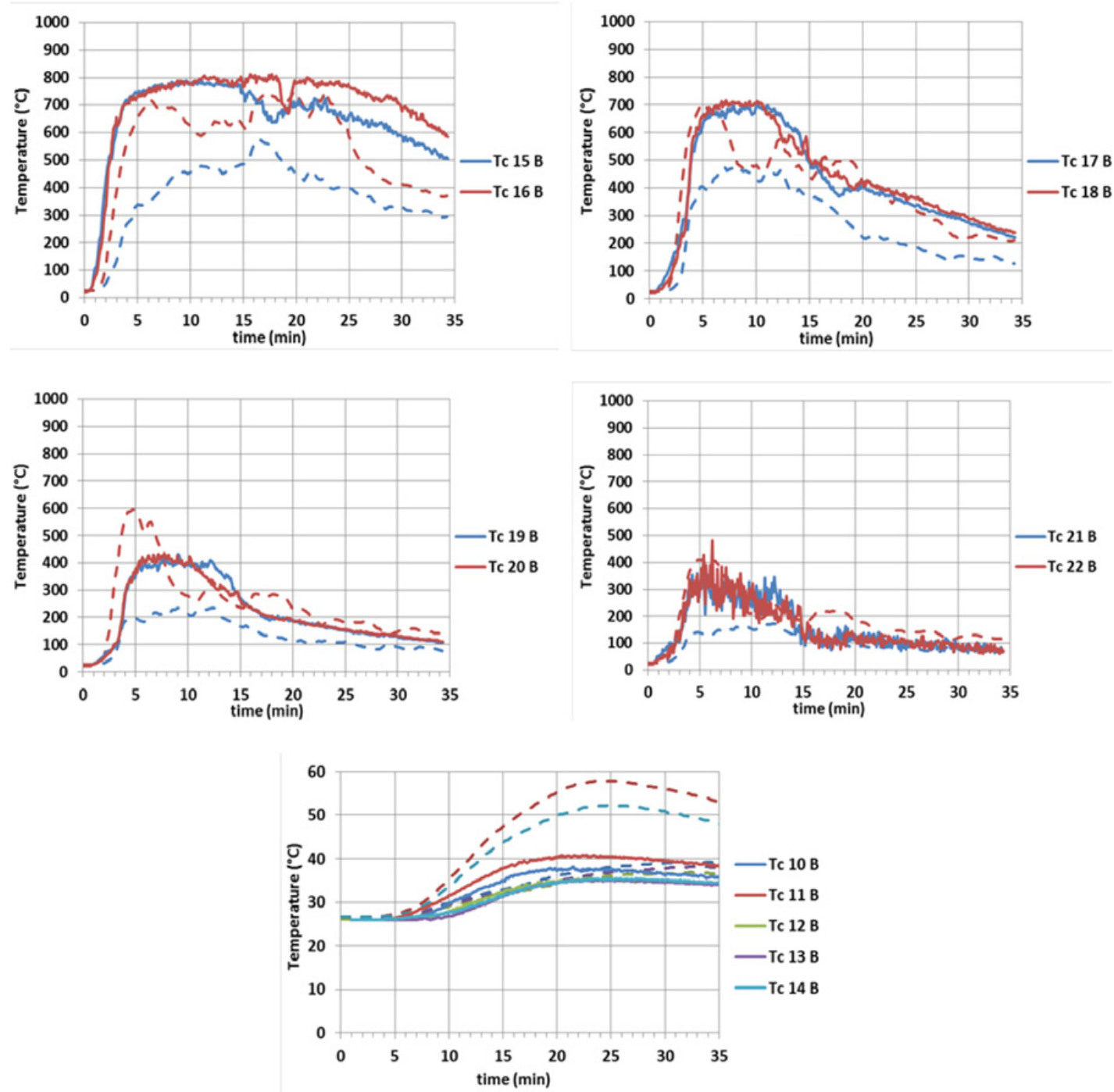

Figure 7. Comparison of experimental (dotted lines) and numerical (solid lines) gas temperatures $150 \mathrm{~mm}$ in front of the facade and in $\mathrm{R}+1$ compartment for the B calibration test of LEPIR2.

The heat release rate (HRR) is evaluated following the model detailed in [9]. It depends on the characteristics of the stack (Fig. 5), the porosity of the crib and the fuel surface. In all cases, the HRR is limited by the ventilation conditions in the compartment. For each stack composing a crib, an individual HRR is calculated.

The evaluated HRR is then prescribed on both fire source modelled. Almost $5 \mathrm{MW}$ are released by the two wood cribs in the R0 compartment. 


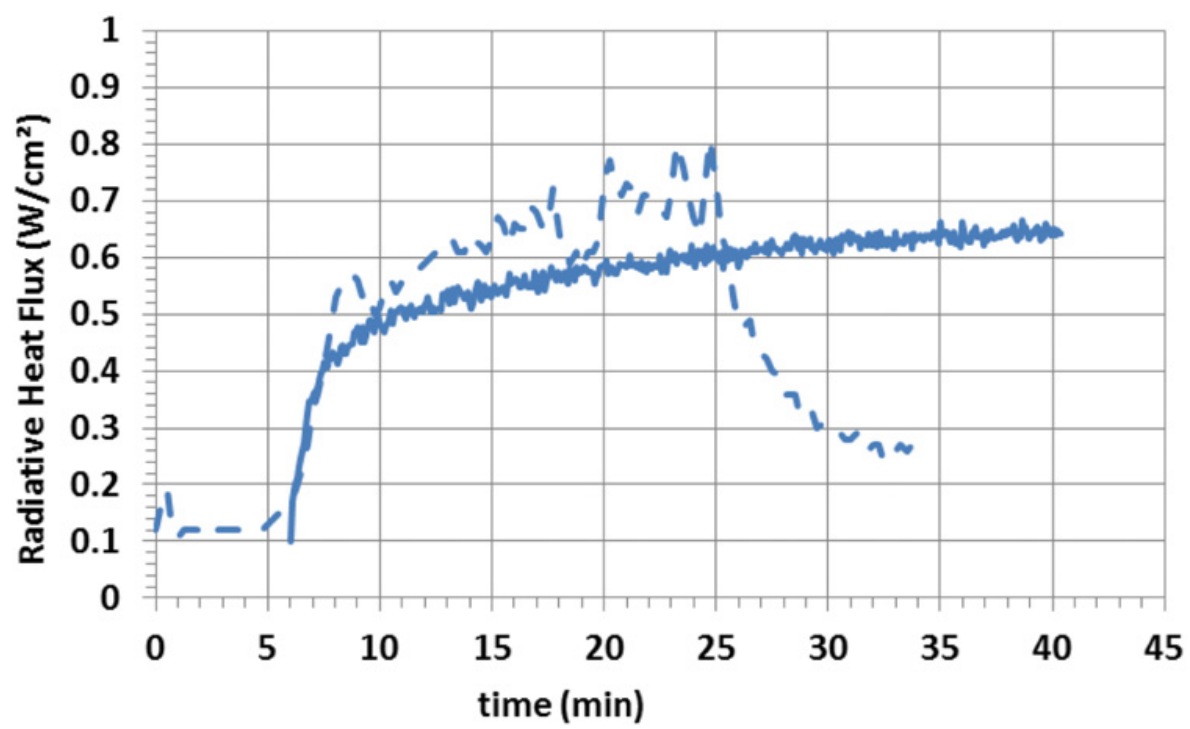

Figure 8. Comparison of experimental (dotted lines) and numerical (solid lines) radiative heat flux $4 \mathrm{~m}$ in front of the facade for the A calibration test of LEPIR2.

\subsection{Results}

External flames come from unburned fuel inside the compartment escaping through openings. In simulations, the total heat released inside the R0 room is close to $2.6 \mathrm{MW}$ at its maximum level. So, 2.2 MW are released outside the compartment.

Predicted gas temperatures located at the facade (see Fig. 2 and Fig. 3) are compared with experimental measurements for test A and test B in Fig. 6 and Fig. 7 respectively.

During test $\mathrm{A}$, the radiative heat flux is measured $4 \mathrm{~m}$ in front of the facade. Numerical results are compared with experimental ones on Fig. 8.

\section{DISCUSSION}

At first, it must be noted that the comparison of experimental results for test A and test B shows an overall good repeatability of the LEPIR 2 tests. Gas temperatures are very comparable at each level on the facade. During test B, a slight asymmetry is observed on the front facade above one window. This can be explained by a side wind on the test's day.

When compared with numerical predictions, good agreement is found for every quantity and both tests. The proposed wood crib model gives correct thermal loads and flames shape near the tested facade.

Temperatures with order of magnitude of $700^{\circ} \mathrm{C}$ are spotted at thermocouples TC 15 to 18 . They are located directly in the external flame near the facade, between $\mathrm{R} 0$ and $\mathrm{R}+1$ opening. Indeed, the simulation shows that the flames well reattach the facade above the R0 openings, due to the absence of obstacles above the windows.

The most critical zone of the facade is then located between windows of $\mathrm{R} 0$ and $\mathrm{R}+1$ levels. The validation criteria to be considered are mainly the temperatures at the junction between floors: $\mathrm{R} 0$ to $\mathrm{R}+1$, and $\mathrm{R}+1$ to $\mathrm{R}+2$. Gas temperatures close to the facade are correctly predicted for each zone. For the thermocouples located up to the R+1 opening, i.e. TC 19 to TC 22, very good agreement is found. These thermocouples are not located directly in the flames, but rather in the ascendant hot gases.

Radiative heat flux in front of the facade is correctly reproduced by numerical simulation. 


\section{CONCLUSION}

CFD simulations have been carried out with the FDS code for two full-scale experiments performed by Efectis France laboratory with the LEPIR 2 facility. The first objective of this study was to validate the numerical model and to evaluate the ability of FDS to correctly predict gas temperatures and heat flux on the tested facade.

The good agreement examined trough the comparison between numerical and experimental results, allows the validation of the proposed wood crib model providing a correct thermal load and a suitable flames shape near the tested facade.

These numerical simulations allow for subsequent evaluation of the tested facade by reproducing the thermal actions imparted to the facade materials. Then, analysis can be done to understand material behaviour or implementation effects in critical zones, thanks to posteriori heat transfer calculations performed with a finite element code.

The next development step for the numerical model will consist in the implementation of the facade construction solution to take into account interaction between the facade product and flames.

\section{References}

[1] Arrêté du 24 mai 2010 portant approbation de diverses dispositions complétant et modifiant le règlement de sécurité contre les risques d'incendie et de panique dans les établissements recevant du public, Journal officiel de la République Française du 6 juillet 2010, texte 31.

[2] Protocole d'application de l'arrêté du 10 septembre 1970 relatif à la classification des façades vitrées par rapport au danger d'incendie.

[3] Fire resistance tests: general requirements; NF EN 1363-1, June 2000.

[4] Fire Dynamics Simulator FDS, version 5.5.1, www.nist.gov

[5] Fire Dynamics Simulator (Version 5) User's Guide, NIST Spec. Publ. 1019-5, 2007.

[6] Fire Dynamics Simulator (Version 5) Technical Reference Guide, NIST Spec. Publ. 1018-5, 2007.

[7] Deshangère, S., "Determination of heating conditions for external structures submitted to fire", PhD Thesis, INSA (Institut National des Sciences Appliquées) Rouen, 2006.

[8] Eurocode 2: concrete structures, Part 1-2, NF EN 1992-1-2, December 2004.

[9] SFPE Handbook of Fire Protection Engineering, Third Edition, NFPA, 2002. 